\title{
Universidad y cooperación: Reconstrucción en Chile tras el terremoto tsunami de 2010
}

Maria Dolores Prieto Peinado maprieto@us.es

Universidad de Sevilla, Sevilla, España

Luz Fernandez-Valderrama

luzfval@gmail.com

Universidad de Sevilla, Sevilla, España

\section{RESUMEN}

El objetivo de esta ponencia es documentar una de las posibles maneras de vincular la Cooperación Internacional al Desarrollo a la práctica docente e investigadora desarrollada en la Universidad de Sevilla. Con motivo del Proyecto de Cooperación "La Reconstrucción tras el terremoto, Tsunami en el Sur de Chile" desarrollado en una 1a fase y financiado por la US, hemos participado en las diferentes realidades de las localidades afectadas por el devastador terremoto-tsunami de 2010, que afectó a las localidades del Sur de Chile. La cooperación la hemos realizado en colaboración con el grupo de investigación del INVI de la Universidad de Chile y a través de las diferentes organizaciones comités de vecinos y ONGS, relacionados con los damnificados. Las cuatro localidades elegidas para la cooperación y el estudio son: Constitución, Llico, Cauquenes y Curicó, situadas en la séptima y octava región y representan ciudades medias y pequeñas, en situación costera y de interior, afectadas por el terremoto-tsunami. En cada una de ellas localizamos las demandas de una población vulnerable, que ha perdido los escasos recursos que en algunas ocasiones tenían y donde el Plan de Re-construcción les ha aislado aún más, a veces negándoles el propio derecho a la ciudad a la que pertenecían, a su barrio y costumbres.
\end{abstract}

PALABRAS-CLAVE: Desarrollo. Cooperación. Reconstrucción urbana. 


\section{UNIVERSIDAD: PROYECTO DE COOPERACIÓN AL DESARROLLO SOBRE EL TERRENO}

Este trabajo nace del interés, por nuestra parte, de restablecer los antiguos lazos de investigación generados con el Instituto de la Vivienda (INVI) de la Universidad de Chile, y permitirnos de nuevo y en la actualidad, el intercambio del conocimiento y de las experiencias entre ambas realidades. Para ello, y con intermediación de la Oficina de Cooperación de la Universidad de Sevilla, pusimos en marcha una primera etapa del Proyecto "La Reconstrucción tras el terremoto/Tsunami en el Sur de Chile: Regeneración de barrios", a través de nuestro grupo de cooperación ARTES, "Arquitectura, Territorio y Salud: Regeneración de Barrios", que, aprovechando la investigación que en esos momentos se estaba realizando por el INVI de la Universidad de Chile, en el "Observatorio de la Reconstrucción" (OR), nos permitió compartir fuerzas y conocimientos a los diferentes grupos de académicos de ambas universidades.

Podemos situar esta Cooperación-Investigación en el ámbito técnico y social, tanto en la formación de recursos humanos, como en el desarrollo del sentido crítico ante la experiencia de la Reconstrucción en una catástrofe natural de gran escala. De esta manera, nos situamos en una modalidad de Cooperación Horizontal, mediante un intercambio en investigación, sobre la oportunidad de una acción para la regeneración de la ciudad ante los desastres naturales. En este sentido, la experiencia de reconstruir al paso del desastre, la tiene sobre todo el país y la población de Chile, pero nuestra participación aporta a la producción de barrio y ciudad, una mirada externa, desprejuiciada y no comprometida a los determinados intereses que allí se están dando de los poderes económicos e institucionales.

Como objetivo general del Proyecto, proponemos re-generar la memoria destruida del Barrio, a través de la cualidad de los espacios colectivos y públicos de la Ciudad y como uno de los objetivos específicos más importantes, proponemos fomentar la acción participativa de los vecinos en el uso y la producción de los espacios urbanos, en las ciudades de Constitución, LLico, Curicó y Cauquenes, a través de facilitarle un mapeado y monitoreo comparativo entre las variantes de la reconstrucción en estas diferentes localidades, donde se visibilice las situaciones de vulnerabilidad, las poblaciones desplazadas, las masificaciones en las periferias con dificultades de movimientos, etc.

La metodología seguida en la selección de los casos de estudio, durante los dos meses aproximados, de estancia que duró el Proyecto, ha sido motivada, en parte, por las relaciones con el INVI, pues, aunque nosotros planteamos las directrices previas, en la selección de ciudades de diferentes tamaños (pequeñas y medianas) y localizaciones (costeras e interiores), en el encuentro con los investigadores del Instituto esta primera selección se concretó, pues se trataba de colaborar en los trabajos que ellos ya venían realizando en muchas de estas localidades.

Dirigimos la cooperación y el estudio a cuatro ciudades, situadas en la séptima y octava región por representar ejemplos de ciudades medias y pequeñas y en situación costera y de interior: Constitución (población media, costera), Llico (población pequeña, costera), Cauquenes (población pequeña, interior) y Curicó (población media, interior). Además, ampliamos las visitas a otras zonas afectadas, como los barrios fundacionales de Talca y las comunas de 
Villa Olímpica y Villa Canadá en Santiago, ejemplos de características muy ejemplares en el desarrollo de los Planes de Reconstrucción. Se puede observar su situación en relación con el terremoto en la Figura 1.

Figura 1 - Representación esquemática de Chile con la localización del epicentro del Terremoto y el área afectada.

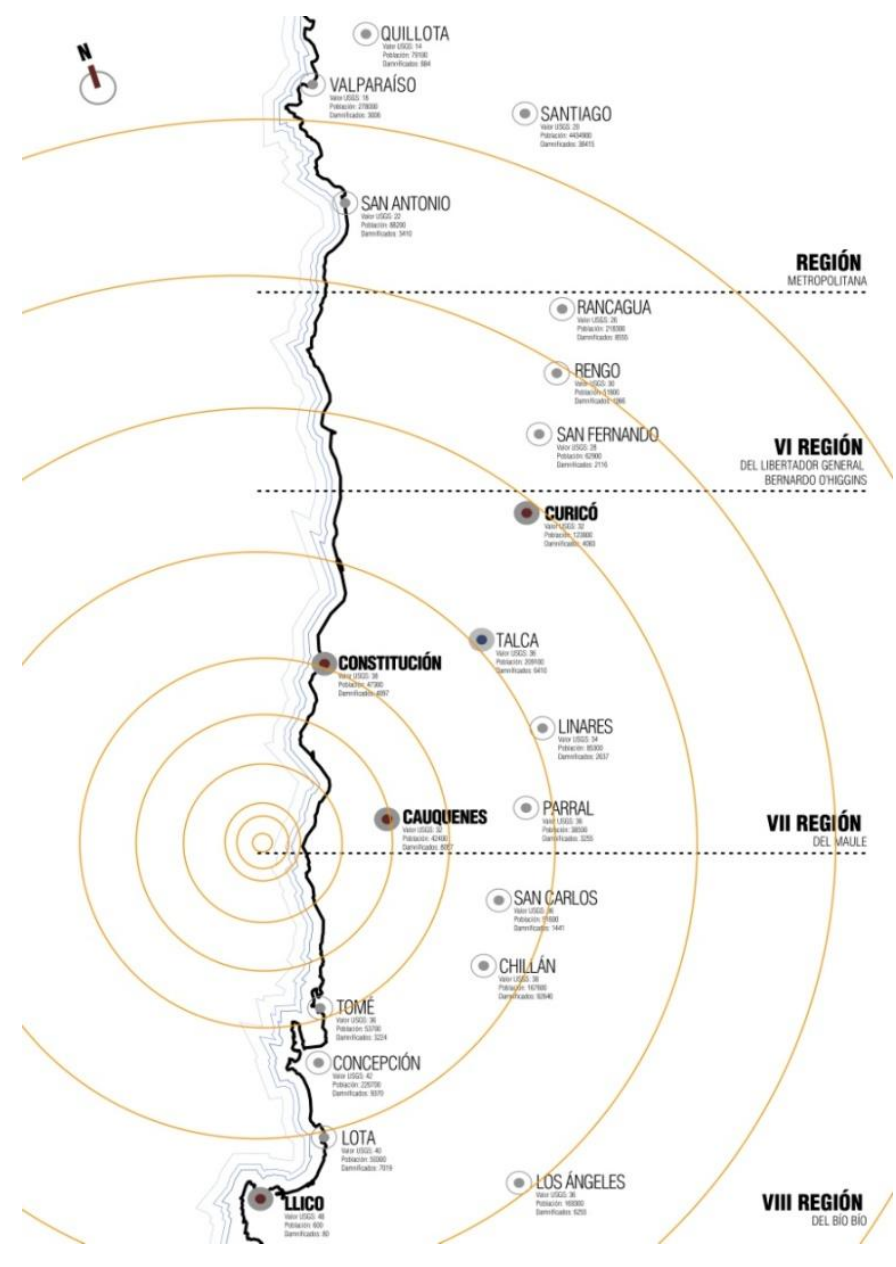

Fuente: Realización propia. En colaboración con Laura Carreño y Rosa Estrada.

Al final de la estancia, re-visitamos el caso de Valdivia, gravemente afectada por el terremoto-tsunami de 1960 , en una fase ya estabilizada tras un proceso propio de reconstrucción, que no contó en absoluto con la atención e inversión por parte de las instituciones públicas como ha ocurrido en el momento actual.

El desarrollo del Proyecto de Cooperación se ha basado en dos líneas de actuación. Por un lado, la puramente investigadora, que se ha realizado a través de reuniones informativas con los investigadores del INVI pertenecientes al proyecto, también tuvimos reuniones con otros representantes de la Facultad de Arquitectura de la Universidad de Chile, así como con diferentes instituciones pertenecientes al Ministerio de la Vivienda y Urbanismo (MINVU), como son: Coordinador Nacional del Programa de Reconstrucción, Secretaría Ejecutiva de 
Campamentos, Coordinador de la Unidad de Análisis-Observatorio de la Comisión de Estudios, Geógrafo de la Comisión Asesora de Estudios Habitacionales y Urbanos (CEHU), además de la consulta a una bibliografía específica y actualizada, monitoreos e informes publicados en diferentes webs relacionadas, entre otros documentos.

Por otro lado, hemos desarrollado la línea de cooperación, donde hemos participado en las reuniones de los comités de vecinos afectados, contestado a sus preguntas y asesorado en las cuestiones técnicas, constructivas y proyectuales, en la medida de nuestras posibilidades. También a través de los miembros de las ONGs participantes directamente en el apoyo y asesoramiento y capacitación a los pobladores afectados.

El aporte de este trabajo a la disciplina de la arquitectura se entiende desde el conocimiento de la ciudad misma, la ciudad como un sistema donde existe una parte física y otra parte experiencia, pero una sin la otra no pueden construir la ciudad. En este sentido, hemos apreciado la cualidad de una ciudad reconstruyéndose y hemos observado los puntos débiles de la reconstrucción chilena a este respecto.

En lo que respecta a los objetivos docentes de relación, entre nuestra cooperación y el entorno universitario, los objetivos se han centrado en conseguir una repercusión directa en el trabajo en las aulas. En nuestro caso, parte de los estudiantes de nuestro grupo de cooperación, ARTES, ha participado en los diferentes proyectos de cooperación realizados, y dirigidos también a otras localizaciones como Cochabamba en Bolivia y Valparaiso de nuevo en Chile. Son estudiantes de Máster o de Fin de Carrera, por lo que nos propusimos llevar la experiencia de la cooperación a las actividades propias de cada docencia.

En nuestro caso, las participantes Laura Carreño Naranjo y Rosa Estrada López, estudiantes que cursan la asignatura de Proyectos Fin de Carrera, tras su colaboración en las actividades propias del proyecto de cooperación en terreno, se encuentran desarrollando sendos Proyectos de Rehabilitación en las ciudades chilenas afectadas por el Terremoto-Tsunami, de Talca y Constitución, materializados en la entrega de Fin de Carrera de la Licenciatura de Arquitectura. Figura 2. 
Figura 2 - Imágenes del Proyecto Fin de Carrera en Talca. Laura Carreño.
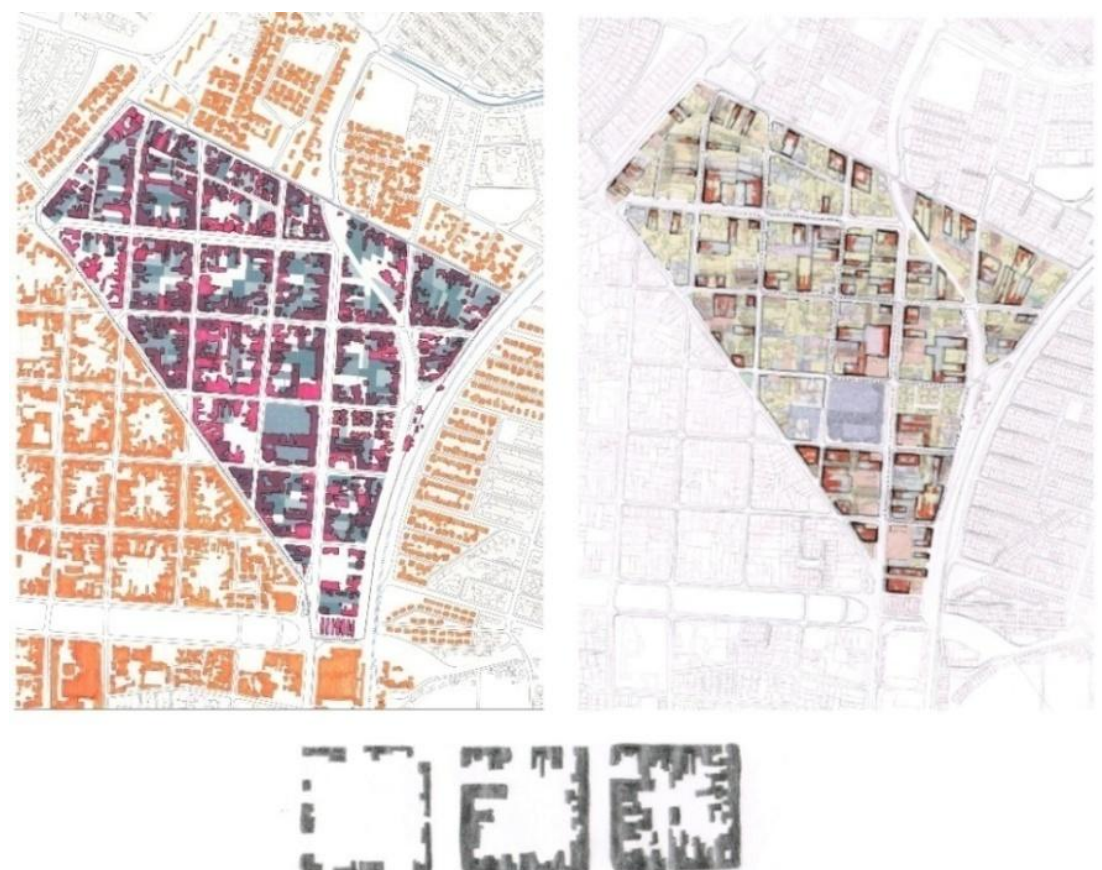

colonización de la manzana desde la construcción del borde y hacia el interior

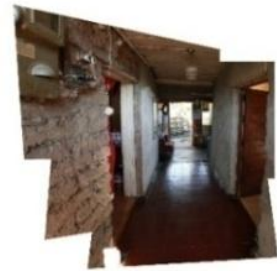

casa-fachada crujia de cierre

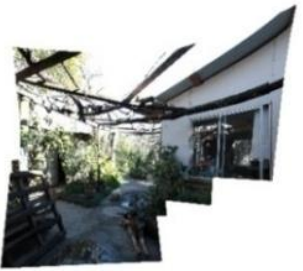

casa-interior crecimientos orgánicos en torno a la parronera

Fuente: Laura Carreño Naranjo.

\section{ANTECEDENTES EN LA SITUACIÓN DE POLÍTICAS DE VIVIENDAS DE INTERÉS SOCIAL A LA CATÁSTROFE DEL TERREMOTO.}

Tras la catástrofe del terremoto, por parte de las instituciones centrales y locales, van surgiendo Planes Maestros de Reconstrucción, cuyo objetivo radica en la atención a los damnificados mediante la dotación de vivienda, a través de nuevos subsidios a los afectados y la intervención de empresas privadas en las construcciones de las mismas.

Antes de entrar de lleno en estos casos, creemos necesario presentar un rápido y escueto recorrido por los antecedentes de las políticas de vivienda social en Chile. Pues desde ahí, comprenderemos mejor las presiones que rodean a los planes surgidos para acometer la regeneración de los territorios devastados por el terremoto-tsunami, sobre todo, debido a las maneras, ya habituales, de 
entender el entorno del habitar y la producción de vivienda, como un producto de mercado, cuantificado en este interés y con la participación directa de las entidades privadas, constructoras y financieras y la confianza puesta en hacer ciudad a través de estos estándares de viviendas.

Dado el volumen de los Campamentos (asentamientos ilegales de infraviviendas), que tenía el país en la década de los años 70, junto a los problemas de índole económico y social que desembocaron en el lamentable Golpe de Estado a Allende, en el año 1974. Bajo la dictadura de Pinochet, se tomaron decisiones para la gestión de políticas que intentaron reducir el déficit de vivienda existente, que a diferencia de las presentadas en el gobierno anterior de Allende, centraron sus objetivos en cuantificar soluciones habitacionales, y en potenciar un sistema de subsidios estatales, unidos a créditos bancarios privados y obligados, el Estado dejaba de construir viviendas y serían las constructoras privadas y la intermediación de los bancos, con sus incentivos adecuados, las que producirían en este sector de extrema vulnerabilidad. El objetivo estaba en dirigir los subsidios a los pobres, pero sólo a aquellos que estaban preparados para ayudarse a sí mismos, evitando la visión del estado paternalista que ayuda incondicionalmente.

Este sistema se hizo perverso cuando las reglas de juego entre estos diferentes actores no protegían a los más vulnerables, de las acciones especuladoras del libre mercado. Lejos de ofrecer viviendas habitables y sostenibles, a una población sin recursos, se generaron problemas a medio y largo plazo de una muy baja calidad habitacional y de entornos poco saludables urbanos. Pues ni las viviendas ofrecían cualidades constructivas, dimensionales, ni el concepto de barrio o ciudad estaba considerado en estas políticas. Además del consiguiente endeudamiento al que eran sometidas las familias en la adquisición de su vivienda, pues en paralelo no existían otras políticas de generación de empleo o mejoras de las condiciones socio-económicas y educativas de estos sectores. Por tanto, este sistema subsidiario de ayudas unidas a créditos bancarios obligados, con la participación de las empresas constructoras privadas, terminaba endeudando a las familias, que se hacían propietarios de viviendas de baja calidad, y cuyo precio a lo largo del proceso se había multiplicado, a veces por cuatro o cinco veces. Aunque existía una ilegalidad en esta actuación, con lo proclamado por el mismo Ministerio de la Vivienda, en el sentido de no poder lucrarse a costa de la población más vulnerable, esto no se respetaba, pues por ejemplo, en la ciudad de Santiago mientras que los prestamos normales para la construcción de viviendas en comunas más pudientes, como Providencia o Las Condes, estaban al $4 \%$ aproximadamente, los préstamos en las comunas periféricas y más pobres, podían llegar a estar al $16 \%$, por ser más pequeños en cantidades y de mayor riesgo para la entidad bancaria.

Mientras que en el panorama internacional, recordemos que acontecía la Conferencia de Vancouver (Canadá) de 1976, que suponía el "escenario para el lanzamiento de la mayor parte de las organizaciones internacionales dedicadas a los asentamientos humanos", las políticas neoliberales en chile se sucedían, eléxito del modelo chileno se valoraba por el resto de los países latinoamericanos en el sentido de que era el único que conseguía bajar el déficit de vivienda. Veinte años después y en vistas a la preparación de los diferentes países para su participación en Hábitat II de 1996, los diferentes países se preparan y 
organizaron diferentes encuentros en un intento de avanzar medidas que llevaran al mejoramiento de las políticas actuales. En Chile, bajo el gobierno democrático de Frei, se reunió la Comisión Económica para América Latina CEPAL, donde se aprobaron el Plan de acción regional sobre asentamientos humanos en América Latina y el Caribe, pero las políticas habitacionales exitosas que el Gobierno publicitaba, seguían teniendo fisuras considerables, cuando se relacionaba con las verdaderas necesidades de sus habitantes, calidad de la vivienda, salubridad del barrio o desplazamientos.

"La política habitacional vigente, reconocida internacionalmente como exitosa, al cumplir 22 años demuestra fuertes debilidades y contradicciones... la calidad de la producción habitacional - no sólo constructiva, sino también en cuanto a la generación de hábitat residenciales adecuados (con equipamientos, áreas verdes, espacios comunes, etc.), los crecientes niveles de deterioro ambiental y de violencia urbana, la carencia de una política global de ordenamiento territorial con capacidad de articular efectivamente el desarrollo económico con el crecimiento de asentamientos humanos ambiental y socialmente sustentables, etc." Se construyen standares de viviendas faltas de cualidad, pues los Programas de vivienda con subsidios existentes en estos momentos, tenían como tipologías fundamentales la vivienda progresiva y la vivienda básica, ésta última pensada más para ámbitos rurales, Figura 3, además se constata la precariedad de sus construcciones, con problemas tan alarmantes como el de las casas Copeva, Figura 4.

Figura 3 - Principales Programas de Vivienda y subsidios de la Política Habitacional Chilena. Año 2000.

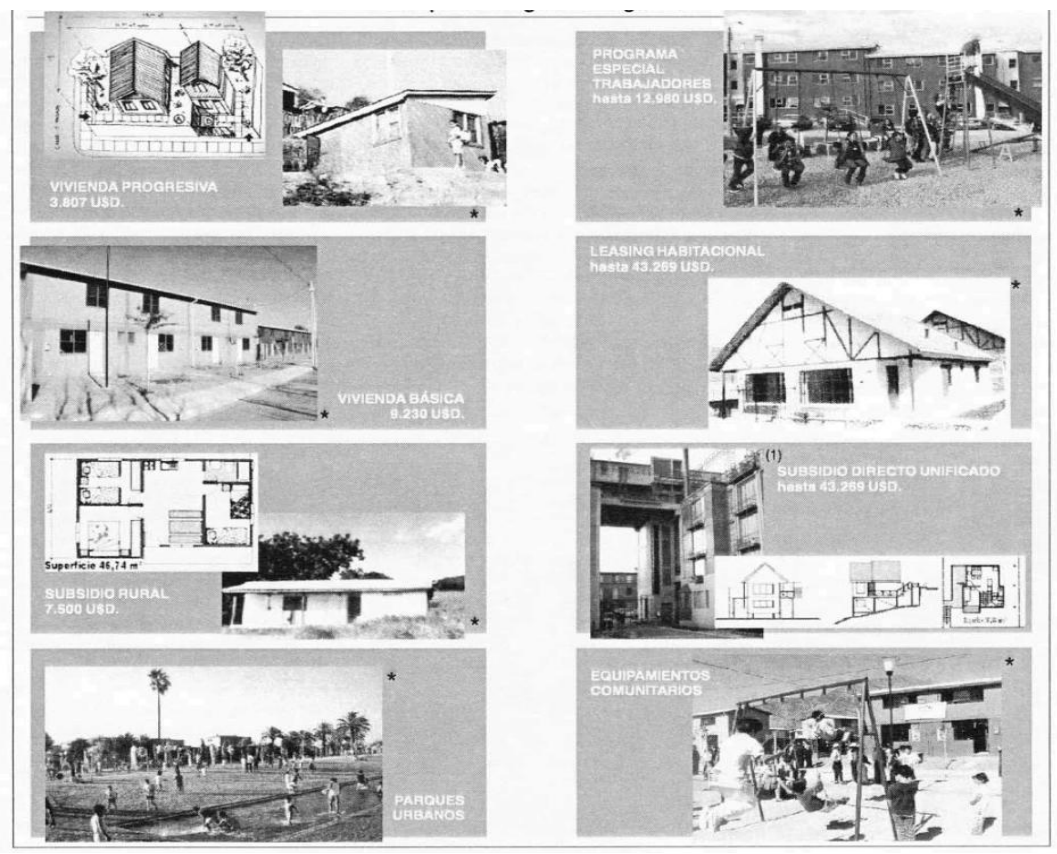

Fuente: Foto Banco de Imágenes del MINVU. Publicadas en Boletín del Instituto de la Vivienda, Chile, 2000 Vól. 15. Sepúlveda, Rubén 
Figura 4 - Imagen de las viviendas Copeva tapadas con plásticos porque se mojaban en su interior.

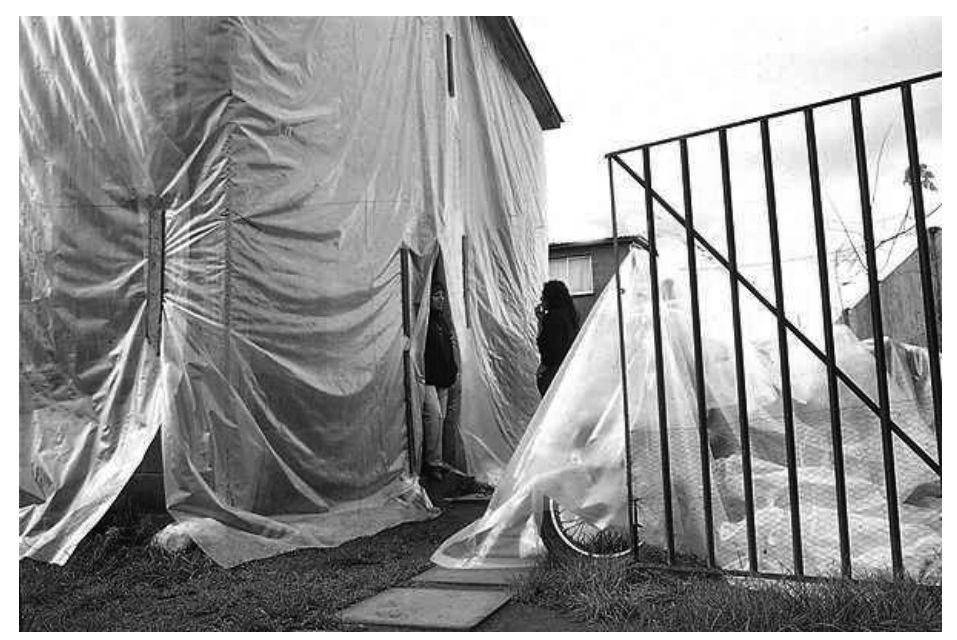

Foto: Periódico El Mercurio (Archivo).

Es en la campaña presidencial del año 99, cuando aparece claramente la necesidad de incluir a la ciudad como eje central en el desarrollo de las políticas de vivienda. Se hablaba de mejorar las ciudades que estaban teniendo unos crecimientos disparatados, se entendía la necesidad de humanizar la ciudad, mejorando las relaciones entre los barrios, evitando los grandes desplazamientos, mejorando las comunicaciones.

Se planteaba la necesidad de nuevos estándares, "ese hito marca una transición desde enfoques fuertemente centrados en aspectos de déficit habitacional y con baja incidencia en los problemas urbanos hacia iniciativas programáticas que buscan abordar temas de calidad en la oferta habitacional y que agregan una preocupación por los efectos antiurbanos de las políticas aplicadas en los periodos precedentes", durante el gobierno de Lagos, se continúa situando el objetivo en la vivienda como elemento aislado, en el objeto construido. Se continúan haciendo políticas, que no alcanzan la complejidad de medidas necesarias que acompañan la verdadera dimensión del habitar, como acción del hombre que necesita de un entorno de vida satisfactorio y la posibilidad de poder hacer propio su hogar.

En este periodo, por tanto las políticas habitacionales tratan sobre todo de las mejoras en las condiciones constructivas y tecnológicas. Pero si fue un periodo donde se iban fraguandoopiniones ciudadanas, sobre la necesidad de favorecer las mejoras urbanas, que se introdujeron en las políticas del posterior gobierno de Bachelet, programas como "Quiero Mi Barrio" nace dentro de los principales compromisos del Programa de Gobierno, que buscaba corregir los defectos de las actuaciones anteriores, "calidad, cantidad e integración", con el objetivo de "contribuir al mejoramiento de la calidad de vida de los habitantes de barrios que presentan problemas de deterioro urbano y vulnerabilidad social, a través de un proceso participativo de recuperación de los espacios públicos y los entornos urbanos de las familias" 
Ha sido desde la concienciación de la ciudadanía en el derecho a la ciudad, desde donde se ha ido exigiendo a los gobernantes la incorporación de mejoras importantes, en objetivos como la calidad de vida, favorecer la integración social y el acceso equitativo de todos los ciudadanos, abordar la recuperación de los barrios y la incorporación de la participación ciudadana, en la búsqueda de ciudades sustentables y con una mayor competitividad urbana.

En el año 2010 insertos en un cambio de Gobierno, a dos semanas de producirse el mismo, donde tomaría la presidencia Sebastián Piñera Echenique, se produjo un Terremoto que alcanzó 8,8 en la escala Richter, con el epicentro situado en el Mar, frente a las localidades de Curanipe y Cobquecura, a $150 \mathrm{Km}$. de Concepción, a 63 kilómetros de Cauquenes. Esta situación tan especial en el gobierno, en pleno cambio de trayectoria política, y a falta de un servicio propio y permanente con un protocolo de acción para el caso de catástrofes, sobrevino en una situación caótica en las primeras semanas y meses.

\section{REFLEXIONES SOBRE LOS PLANTEAMIENTOS, GESTIÓN Y EJECUCIÓN DEL PLAN DE RECONSTRUCCIÓN DEL GOBIERNO DE CHILE.}

De igual manera os ponemos en antecedentes de cómo se ha llevado la gestión y ejecución del Plan de Reconstrucción, dirigido desde el Gobierno. Para ello, partimos de los datos aportados por las diferentes entidades consultadas, tanto gubernamentales como locales o asociaciones de damnificados y ONGs, consultadas durante nuestra estancia.

El Plan de Reconstrucción puesto en marcha desde el Ministerio de Vivienda y Urbanismo (MINVU), apareció, aproximadamente, tres meses después del terremoto-tsunami, y se articula en tres escalas:

1) Reposición de vivienda destruida

En esta primera escala se acometen los subsidios a los damnificados para la reparación, rehabilitación, reconstrucción y construcción de nueva vivienda. La construcción de las mismas se lleva a cabo por constructoras privadas.

Las construcciones de nueva planta podían realizarse en sitio propio o en nuevos entornos, dependiendo de diferentes circunstancias.

Los actores intervinientes en el proceso son: SEREMI, SERVIU, municipalidad, sector privado, y comités de vivienda formados entre los propios pobladores.

2) Plan de gestión de aldeas

En los casos de movilización de la población afectada o en los casos en los que mientras se reforma su casa no tuvieran donde estar, se plantean asentamientos de emergencia en zonas seguras, con mediaguas $(4 \times 6 \mathrm{~m})$ como solución habitacional transitoria.

3) Planes maestros

Se formulan diferentes Instrumentos de planificación territorial, que redactados y financiados por empresas privadas, con interés en el territorio, en la mayoría de los casos porque tenían industrias asentadas en las cercanías afectadas. Estos planes son destinados a orientar la reconstrucción de los núcleos 
urbanos (no se trata de una legislación, sino de ofrecer una imagen de la dirección previsible o deseable del crecimiento).

En la actualidad, existe la voluntad de redactar una Ley de Protección Civil ante los desastres, con el fin de definir cómo debería reaccionar el país ante situaciones similares, basada en protocolos y planes de emergencia, porque, recordemos que en los años 40 existía un Ministerio de Reconstrucción, el cual había desaparecido.

Entendemos pertinente hacer otra reflexión previa sobre el necesario sentido y escala que el término re-construir, tiene para nuestro trabajo, sobre todo, después de una catástrofe de las dimensiones de la que nos ocupa. Primero es necesario conocer el daño producido, para a partir de ahí pensar en cuáles deberían ser los actores y atributos de una escala integral de la re-construcción. Por supuesto que basta con imaginar algunos de estos desastres y rápidamente percibimos la magnitud de los daños materiales, pero no menos importantes son los daños a las personas, los físicos y los emocionales son los realmente fuertes. En principio están los muertos y desaparecidos, familias rotas imposibles de recuperar, que necesitaran una explicación de porqué la Naturaleza, aquella a la que acostumbramos a ver avasallada por la presencia humana en infinitud de ocasiones, despliega su magnificencia sobre la mortal, inevitable por otro lado, condición humana.

Después estará la desaparición de toda la memoria, porque las pérdidas materiales, no solo se llevaron la vivienda, o la calle, sino todo lo que en ella se había creado a lo largo de años de convivencia, se llevaron las horas de recuerdos además de los rincones de los encuentros, en definitiva se llevaron la experiencia del barrio (siendo la demanda de la población en este contexto, la demanda general que afrontamos en el Proyecto).

Tras la catástrofe, la gran pregunta que se hace inevitable es, cómo se recupera, toda esta pérdida, pues sabemos que recuperarlo tal cual será imposible, pero estamos en la labor de ayudar a paliar estas pérdidas en la medida de lo posible.

Por esto, en esta enumeración de grandes pérdidas, no podemos olvidar todas las otras estructuras urbanas destruidas, desde las viviendas, los hospitales, las escuelas, las calles y carreteras, y un largo etcétera, que evidencia una primera y urgente atención a los heridos, cobijo a los que han quedado en la calle y aliento a los que han perdido todo. Todo el panorama del día después, pero la re-construcción integral también habrá de resolver como se reincorporan estas personas, a la vida activa, como se las devuelve a la sociedad a la que pertenecían.

Querer renombrar la amplitud del desastre que supuso el terremoto y tsunami, no tiene la pretensión de volver al dolor y al drama, sino todo lo contrario, tratar de reconocer la complejidad y diversidad de las situaciones que hay que tratar, para poder volver al principio de nuestra disertación, re-construir es plantear una estrategia integral de actuación que contemple la complejidad y diversidad de lo pretendido.

Habremos de contemplar actuaciones de urgencias personales, físicas y emocionales, con tratamientos sanitarios adecuados, urgencias de alojamientos provisionales, alimentación y educación. Porque desde el minuto dos, el intento 
por volver a una posible rutina de continuidad se hace necesario. Asesoramientos jurídicos, que indiquen cómo actuar en estos casos de pérdidas de registros, de propiedades... En definitiva se necesita, un Plan Integral dotado de un protocolo de estrategias inmediatas, estrategias a corto plazo, a medio plazo y a largo plazo. Estos plazos han de cruzarse con las diferentes actuaciones y actores, directrices coordinadas desde no solo el Ministerio de la Vivienda y Urbanismo, sino también desde el Desarrollo Social, desde la Educación, la Sanidad, la Economía, la Cultura y el Medio Ambiente, incluyendo a los actores locales, y a los grupos de vecino damnificados.

La cualidad del problema se hace tan imprescindible como la cuantificación, porque de ella se derivaran las estrategias para los diferentes tipos de asistencia que han de confluir, desde la sanitaria, pasando por la psíquica, la social, la jurídica, la laboral, la educacional, entre otras.

Este Plan de estrategia Integral ha faltado, a nuestro entender, aunque reconocemos el gran esfuerzo realizado, la atención psico-social o jurídica ha faltado, por ejemplo. El Plan de Reconstrucción no ha atendido las situaciones derivadas del trauma post-desastre que sufren los pobladores (el acontecimiento puntual, la no respuesta, la desinformación...); estas cuestiones han tenido que ser abordadas por las ONGs o de la iniciativa de los propios pobladores, organizados en comités.

Recordemos que uno de los pilares del Plan de Re-construcción del Gobierno está en los subsidios a los damnificados. Desde el MINVU se han ofertado diferentes tipos de subsidio (algunos existentes con anterioridad, otros propuestos a raíz del desastre): reparación de viviendas, banco de materiales, construcción de viviendas en sitio propio o nuevos terrenos, vivienda social. Sin embargo, el acceso a los subsidios, en ocasiones ha sido imposible, pues la población que no puede justificar la propiedad no puede acceder, o como es el caso de las familias con poca capacidad de endeudamiento, o las que viven en condición de arrendatarios o allegados sin papeles.

Y la apuesta mayor del Plan, radica en la participación de la empresa privada. El capital privado está presente en la escala vivienda y los Planes Maestros, considerando la vivienda y la ciudad como productos de inversión y abriendo la posibilidad a la especulación. Como resultado, se ha asistido al enriquecimiento de empresas promotoras, constructoras, de materiales, o con poder en los municipios y con posibilidades de intervención y presión en la redacción de los Planes Maestros.

Por otro lado, la vivienda resultado del Plan de Reconstrucción, en muchas ocasiones, presenta carencias en su concepción y materialización. Por una parte, deficiencias a nivel de proyecto en cuanto a la calidad espacial interior, exterior y de los espacios colectivos y por otra, problemas con respecto a la calidad de los materiales, las soluciones constructivas escogidas, la ejecución y el incumplimiento de plazos, etc.

Si nos fijamos en la definición del espacio público reconstruido, observamos que no recibe la adecuada atención desde el Plan, pues la mayoría de las soluciones habitacionales colectivas proyectadas se resuelven como condominios completamente aislados de la trama urbana circundante y las propuestas para el equipamiento y la obra pública de plazas y jardines es escasa o nula. 
En los casos de las localidades costeras afectadas por el tsunami, como Constitución o Llico, la población ha sido desplazada de sus barrios de origen hacia las aldeas de emergencia (teóricamente temporales, aunque aún quedan familias en esta situación) -normalmente ubicadas en cerros alejados del núcleo urbano- y posteriormente a las viviendas sociales correspondientes -igualmente, localizadas en las periferias-; lo que supone una alteración radical de las relaciones y hábitos de la vida de barrio.

Toda esta serie de características han producido unos barrios con tipologías y calidades constructivas inadecuadas, edificación masiva, vacíos urbanos permanentes por no rentables o faltas de recursos de los propietarios, deslocalizaciones de las familias, que han generado problemas de inseguridad, hacinamientos y desprotección, que en muchas ocasiones desembocan en una des-conexión social y urbana.

\section{CASOS DE ESTUDIO}

\section{CONSTITUCIÓN}

La comuna de Constitución se sitúa en la provincia de Talca, en la VII Región del Maule y abarca una superficie de $1.343,6 \mathrm{~km}^{2}$ y una población de 46.081 habitantes. La mayor afectación en la ciudad de Constitución fue debida al Tsunami posterior. Después de la catástrofe el $80 \%$ del Centro de la Ciudad quedó destruido o tuvo que ser demolido por peligro de derrumbe. Aproximadamente según los registros del MINVU, 1200 lotes fueron afectados y alrededor de 2000 damnificados. La visita por la ciudad después de tres años y medio, continúa siendo desoladora, pues las demoliciones han generado grandes vacios que ofrecen una percepción de ciudad rota.

En el proceso de dotar de vivienda a los damnificados que pudieran acreditar su situación de propietarios, se crearon las Aldeas temporales, de las cuales tan sólo había desaparecido en su totalidad la Aldea 27F. La representación de la zona afectada por el Tsunami se observa en la Figura 5, así como la ubicación y el volumen aproximado de las Aldeas temporales, representadas con un círculo y las nuevas construcciones, representadas con un negro de mayor intensidad.

A continuación presentamos una síntesis de los datos obtenidos en las visitas realizadas, que tras el monitoreo de subsidios y construcciones nos permitió realizar los mapeados correspondientes:

- Aldea Antofa,

Procedencia: Aldea creada para las familias residentes en los departamentos del edificio Francisco Mesa Seco que colapsó con el terremoto, y viviendas de la ciudad. Situación: En zona de periferia, el cerro junto al cementerio. Descripción: Se entregaron 20 viviendas, sin divisiones ni revestimientos, con agua. Una sede donde se hacían las reuniones con el MINVU. Primero se colocaron baños químicos y después un conteiner con duchas y baños. Solicitaron al MINVU una lavandería. Las familias son las encargadas de terminar las viviendas en cuanto a revestimientos, crear las divisiones, agrandarlas comprando otras mediaguas. 
Una vez que reciben el departamento venden las mediaguas, o todo lo que puedan reciclar de ellas. Reubicación: 17 de las familias se han trasladado a los departamentos de la IV etapa de Centinela. Las otras 3 están esperando al proyecto Villa Verde de viviendas unifamiliares.

- Aldea $27 \mathrm{~F}$

Procedencia: Todo el pueblo. Situación: Entrada de la ciudad, periferia, pero no conocemos la ubicación exacta. Descripción: La aldea más grande que se construyó, pero ya había desaparecido en nuestra visita. Reubicación: La mayor parte de la población afectada se trasladó al proyecto Bicentenario.

- Aldea La Poza

Procedencia: Borde costero de la ciudad (la poza). Situación: En la misma parcela donde se situaban las viviendas, en el borde costero. Descripción: Algunas de las familias se alojaron en mediaguas, pero actualmente la mayoría vive de alquiler esperando el proyecto Villa Orillas del Maule. Se construyó una sede de reunión. Mientras esperaban las mediaguas, se le dio a cada familia una tienda de 4x4 m. Reubicación: Proyecto Villa Orillas del Maule.

\section{- Proyecto Bicentenario}

Situación: En el mismo barrio del Bicentenario. Periférico. Viviendas: 4000 viviendas en condominio social. 4 viviendas por planta, cuatro plantas. Descripción: Proyecto de vivienda social posterior al terremoto de cuatro torres. Para el terremoto se amplió a siete sectores para realojar damnificados de todas partes del pueblo. 
Figura 5 - Planimetrías de Constitución. De arriba abajo: 1. Antes del Terremoto. 2. Afectación Terremoto-Tsunami 2010. 3. Actual 2013. Aldeas y Asentamientos.
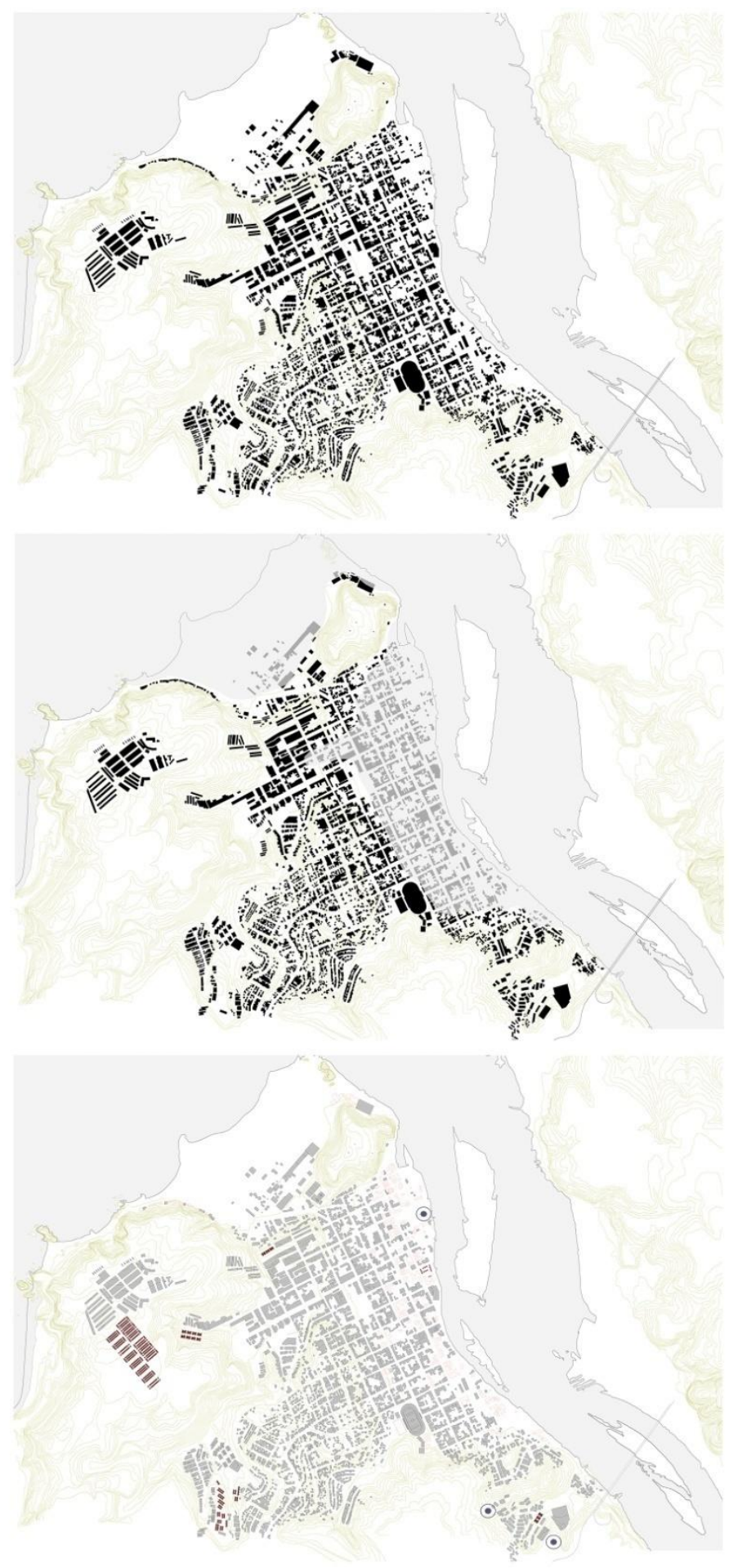

Los primeros desplazamientos se hicieron a este sector. Muchas familias se alojaron aquí por no esperar a la reconstrucción de sus viviendas. Son muy difíciles las características sociales de este barrio, convertido en "gueto", sin 
transporte público y con escasos servicios. Las primeras viviendas se entregaron al año del terremoto y las últimas hace ocho meses.

- Proyecto Villa Verde

Situación: detrás de Villa Huquén. Viviendas: 484 viviendas 50\% damnificados con subsidios $50 \%$ trabajadores de la empresa de maderera "Arauco". Viviendas unifamiliares algunas con plan de ampliación, otras no. Descripción: Llevan meses retrasando la entrega de las viviendas. Obras no quiere recepcionar por problemas de desnivelación. En vivienda social lo máximo que se puede construir son $52 \mathrm{~m} 2$ con posibilidad de ampliación hasta $57 \mathrm{~m} 2$.

- Proyecto Altas Cumbres (Villa Las Cumbres)

Situación: periferia, en la zona alta frente al mar. Viviendas: 220 viviendas sólo para damnificados en condominio social. 4 viviendas por planta en 5 plantas. Descripción: Reside gente de todo el pueblo. Se inauguró el $27 \mathrm{~F}$ de este año 2013.

- Proyecto O'higgins

Situación: periferia. Viviendas: 40 viviendas en condominio social. 4 viviendas por plantas en cuatro plantas. Descripción: Viviendas sociales de 84 viviendas que colapsó con el terremoto, parte de las familias van al proyecto de villa verde.

- Proyecto Pres

Proyectos realizados del Plan de Reconstrucción Sustentable (PRES) de Constitución: Se había construido la Estación de Bomberos, la Pista de Fútbol y parte de un Carril bici que delimita la expropiación del borde costero.

\section{LLICO}

Se trata de una localidad del borde costero de la VIII Región del Bio Bio, perteneciente a la provincia de Arauco, con una población de 600 habitantes que fue arrasada casi en su totalidad por el Tsunami. La población fue trasladada provisionalmente a la Aldea Nueva Esperanza y de ahí fueron siendo realojadas en nuevas viviendas.

En esta población se combinó en subsidio dado a las familias damnificadas con los subsidios anteriores de vivienda social para las rentas bajas. La representación de las áreas afectadas se observa en la Figura 6, donde, en el estado actual, se representa la localización de la Aldea Nueva Esperanza con un círculo y el proyecto de Viviendas sociales con un tono sepia de mayor intensidad.

\section{Aldea Nueva Esperanza De Llico}

Procedencia: Damnificados del pueblo total 150 familias, la mayoría tenían sus viviendas en el sector costero. Situación: Junto al cerro, lo más alejado de la costa. Descripción: Se entregaron 22 mediaguas (entregadas por Techo para Chile) y una sede para las reuniones del pueblo (por el MINVU). Son prefabricados de mediaguas con cubierta de Zinc y elevadas $10 \mathrm{~cm}$ sobre el suelo.

En el pueblo existían muchos más damnificados que solicitaron subsidios de reparación o subsidios de alquiler. La situación en esas viviendas era mucho peor 
que en la aldea, ya que no contaban con luz ni agua, y el problema más importante del pueblo que no existe una red de tratamiento de aguas negras. Cada vivienda tiene que construir una fosa séptica.

Las ayudas que se fueron solicitando y construyendo en la aldea eran para beneficiar al pueblo entero. Se solicitó una lavandería (empresa ARAUCO), el invernadero (FOSIS), una sede mayor (CÁRITAS CHILE), chimeneas para todas las mediaguas y una pista de fútbol. Reubicación: Todas las familias residentes en mediaguas están esperando su vivienda del proyecto de viviendas sociales.

- Proyecto De Viviendas Sociales

Situación: frente a la aldea. Viviendas: 80 viviendas en total, 52 damnificados y 22 régimen regular (subsidio normal con ahorro, anterior al 27F). Descripción: Viviendas unifamiliares de $48 \mathrm{~m} 2$ en una parcela de aproximadamente $168 \mathrm{~m} 2$. Algunas viviendas se han construido en sitio propio y han podido cambiar un poco las viviendas en cuanto a revestimientos. El proyecto de urbanización contaba con la pavimentación del espacio público, pero los vecinos solicitaron que ese presupuesto se destinara a la construcción de una planta de tratamiento de aguas. (Solución anterior una fosa por cada dos vecinos). La situación del proyecto es un poco complicada al estar situada junto al cerro de arena arcillosa que se derrumba con las lluvias. Han colocado muros de contención pero parecen insuficientes.

\section{- Proyecto Pres}

Los Proyectos programados por el Plan de Reconstrucción Sustentable (PRES) de Llico, proponían la reposición y ampliación del Camino Al Piure, la construcción de espacios públicos y la construcción y establecimientos del Bosque de Protección Arauco con el objetivo de mitigar la erosión de una nueva catástrofe. Estos proyectos estaban aún sin desarrollar.

- Proyectos Participativos Realizados En El Pueblo

La mayoría de los proyectos que se han realizado a nivel general en el pueblo han sido de infraestructuras, ya que se destruyeron los dos puentes que comunicaban los pueblos costeros (Lavapiés, Llico, Tubul y Arauco).

Quieren hacer un bosque de mitigación, pero el pueblo quiere una costanera que haga un poco de protección del borde, sin bosque, ya que la ola en el caso 27F llegó lateralmente. 
Figura 6 - Planimetrías de Llico. De arriba abajo: 1. Antes del Terremoto. 2. Afectación Terremoto-Tsunami 2010. 3. Actual 2013. Aldeas y Asentamientos.

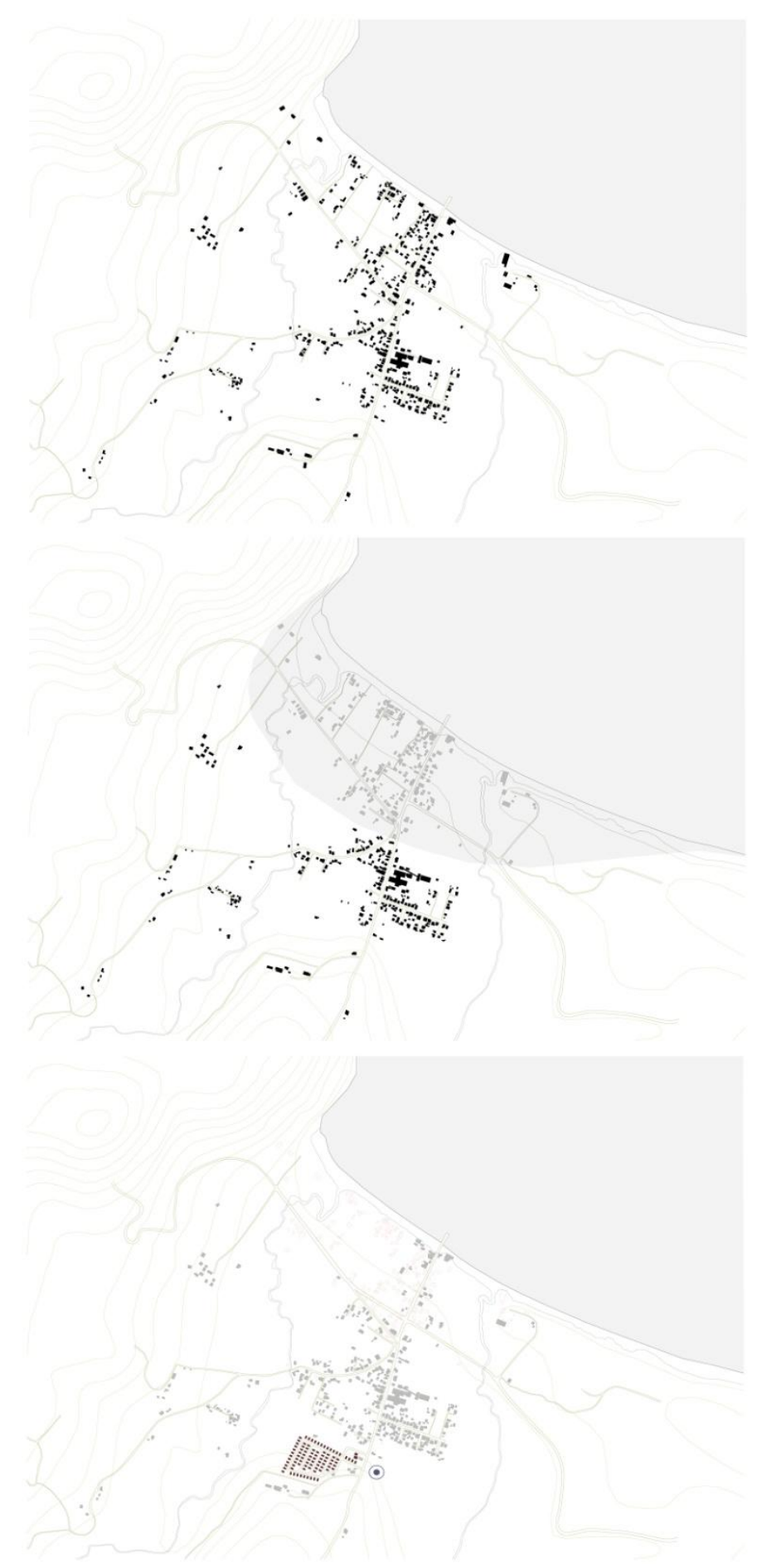

Fuente: Realización propia. En colaboración con Laura Carreño y Rosa Estrada. 


\section{CAUQUENES}

La provincia de Cauquenes está ubicada en la parte suroeste de la VII Región del Maule, a una distancia de $350 \mathrm{~km}$ de Santiago. La ciudad es interior y tiene una población de 41.217 habitantes. En este caso el terremoto afectó a barrios fundacionales, con el componente de un valor patrimonial. Las características propias de estos barrios se observan no sólo en sus edificaciones, sino también y en mayor medida en la manera de "habitar" de sus vecinos, sus costumbres y comportamientos suponen un valor en la conservación de ciertas pautas tradicionales, amenazadas por la lectura simplista que se hace desde las propuestas de la Reconstrucción, en la tipología de fachada continua.

En su mayoría son parcelas grandes, aproximadamente de $20 \mathrm{mts}$ de fachada, donde se han ido haciendo sitio los "allegados" (familiares que vienen del campo a la ciudad y se quedan a vivir mediante sucesivas subdivisiones dentro de las parcelas familiares), esto además, supone un problema de exclusión porque los allegados no tienen papeles de propiedad y los subsidios están pensados exclusivamente para aquellos que son propietarios.

Por otra parte, el encuentro del grupo familiar se produce en los patios interiores, a la sombra de los parrales, espacios que son de gran importancia simbólica, pues son los centros de reunión del grupo familiar, desahogo de juegos y otras tareas compartidas, pues estos espacios no son considerados en la Reconstrucción propuesta.

De igual modo, apuntar el valor que la calle tiene para los vecinos de estos barrios, como lugar de convivencia vecinal, son el lugar de las historias compartidas, costumbres que se pierden cuando los vecinos son desplazados.

También es conveniente recordar, que estos barrios recogen una pluralidad social, que enriquece el intercambio, donde los ciudadanos de rentas inferiores conviven con similares comodidades de cercanías, servicios urbanos que el resto de los vecinos, pues si se desplaza a los más vulnerables, ellos pierden en calidad de vida, pero el barrio también pierde en diversidad, solidaridad, etc.

No olvidemos, en paralelo, algo común a muchas de estas localizaciones, que es la presión que reciben para obligarlos a una venta de emergencia, barata y con el beneficio de los inversores al acecho de una buena plusvalía.

Es evidente que la escala de barrio no ha sido objetivo del Plan de Reconstrucción, inclinándose éste más, hacia iniciativas de construcciones en condominios de departamentos en altura en las áreas periféricas, cercados y cerrados, aislados de la calle y ajenos a las interacciones urbanas.

De igual manera y entrando de lleno en el aspecto tipológico y constructivo, la opción de fachada continua que se ofrece parece más una teatralización que busca resolver la primera imagen que una reflexión tipológica de una vivienda tradicional en adobe. Los aleros (como escaparate) son de tejas, cuando las cubiertas son de chapa de precaria construcción, fachada que, por continua, se alarga creando unos falsos crecidos de muros que simulan ser fachadas, vacías, Figura 7, porque en estas tipologías estándares, para nada se ha tenido en cuenta la realidad de estas viviendas, lo particular de las mismas, por lo que realmente se las puede considerar patrimoniales. 
Figura 7 - Trasera de Vivienda de fachada continua en Cauquenes.

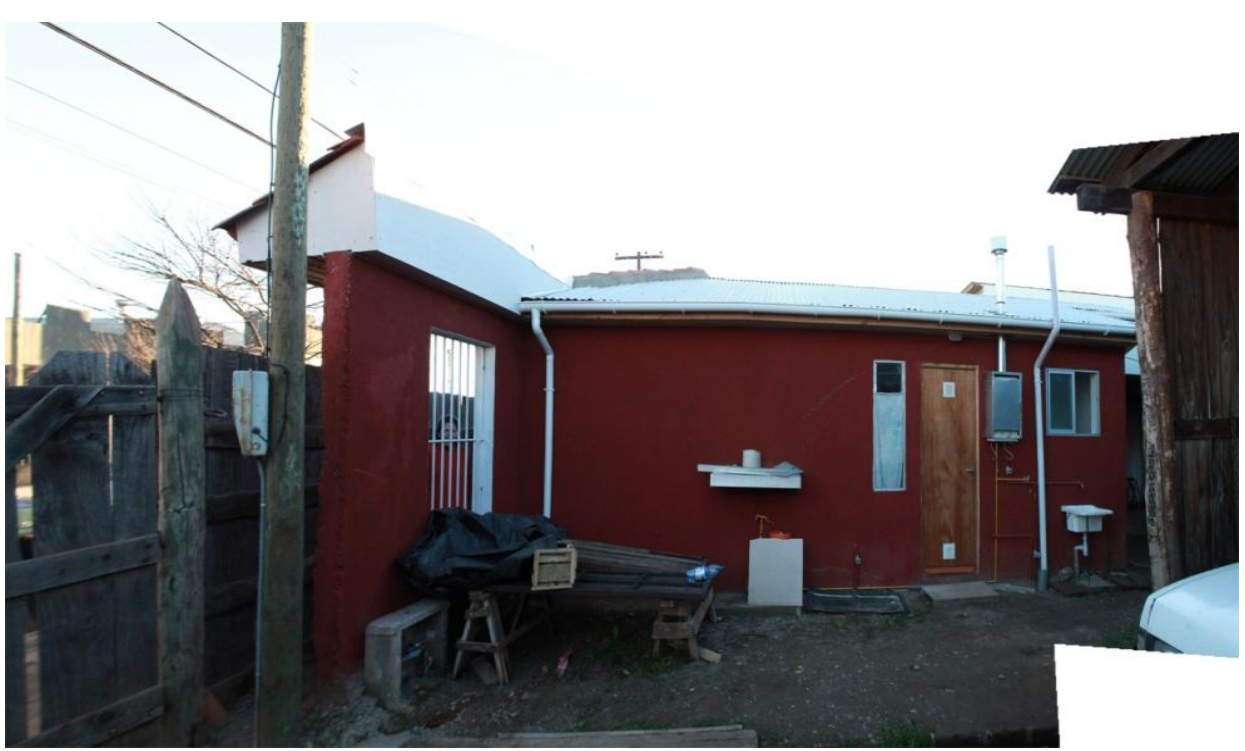

Fuente: Realización propia. En colaboración con Laura Carreño y Rosa Estrada.

La representación de las áreas afectadas se observa en la Figura 8.

A continuación presentamos una síntesis de los datos obtenidos en las visitas realizadas.

- Proyecto De Protección Patrimonial Calle Yungay

Situación: Calle Yungay desde Santa María hasta el final de la calle hacia el poniente.

Subsidios en zonas patrimoniales:

- Subsidio de reparación: Consistieron en un Subsidio de reparación + un Subsidio extraordinario para zonas patrimoniales.

- Subsidio de reconstrucción: Consistieron en un Subsidio de reconstrucción + un Subsidio extraordinario patrimonio + Adicional de demolición.

La normativa local obligaba a respetar la fachada continua del callejero. Con tal objetivo se produjeron varios modelos estándares que escenificaban una cierta parodia de las viviendas originarias, con la obligación de las cubiertas de tejas. Se propusieron dos tipos diferentes, viviendas de fachada continua en esquina, dejando una cubierta "mediterránea" o de fachada continua dejando un pequeño corredor. 
Figura 8 - Planimetrías de Cauquenes.
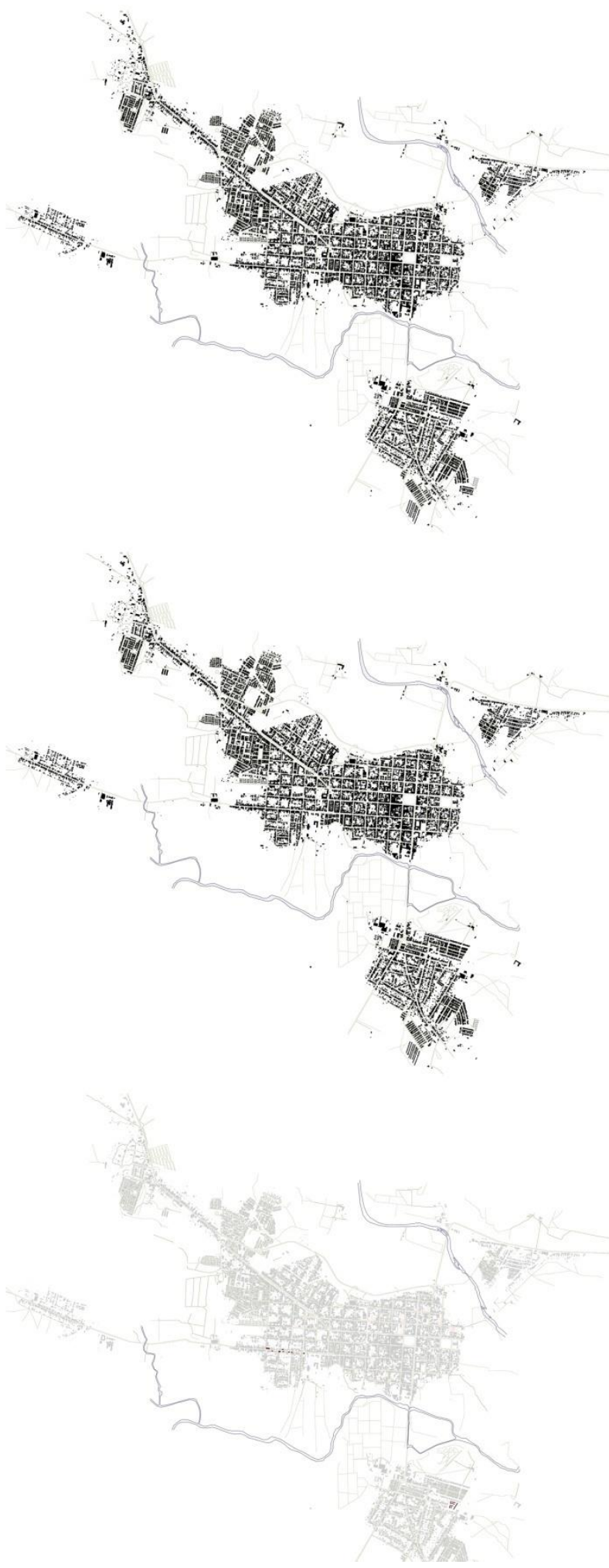

De arriba abajo: 1. Antes del Terremoto. 2. Afectación Terremoto 2010. 3. Actual 2013. Reconstrucción patrimonial y Condominio.

Fuente: Realización propia. En colaboración con Laura Carreño y Rosa Estrada. 
El comité de vecinos del barrio Yungay estaba muy disconforme con la reconstrucción que se está realizando de sus viviendas por la mala calidad de las mismas y por problemas en la construcción, en cuanto a los materiales que se especificaban en los proyectos, pues no coinciden con los que se utilizan en obra.

- Proyecto De Viviendas Barrio La Estación

Situación: En el barrio la estación. Céntrico. Viviendas: 70 viviendas unifamiliares de dos plantas entregadas en bruto sin revestimientos interiores, solo exterior. Sin sede de juntas de vecinos. Descripción: $80 \%$ para damnificados y $20 \%$ para subsidios regulares. Los damnificados provienen de: barrio la estación, población Oyola, población laurel y de viviendas rurales. Las viviendas fueron entregadas hace dos meses y los habitantes están muy contentos en general ya que, aunque las viviendas se encuentran fuera de la ciudad, están en un barrio que cuenta con servicios muy próximos.

\section{- Proyectos Participativos Realizados En La Ciudad}

A nivel de ciudad, en Cauquenes no existe un PRES por falta de una empresa que la financie. Las únicas reconstrucciones de edificios públicos han sido realizadas por empresas privadas. Nada por parte del municipio.

\section{CURICÓ}

Perteneciente a la Región del Maule en el Valle Central, tiene una población de 147.017 habitantes.

La representación de las áreas afectadas se observa en la Figura 9. 
Figura 9 - Planimetrías de Curicó. De arriba abajo: 1. Antes del Terremoto. 2. Afectación Terremoto 2010. 3. Actual 2013. Condominios visitados.

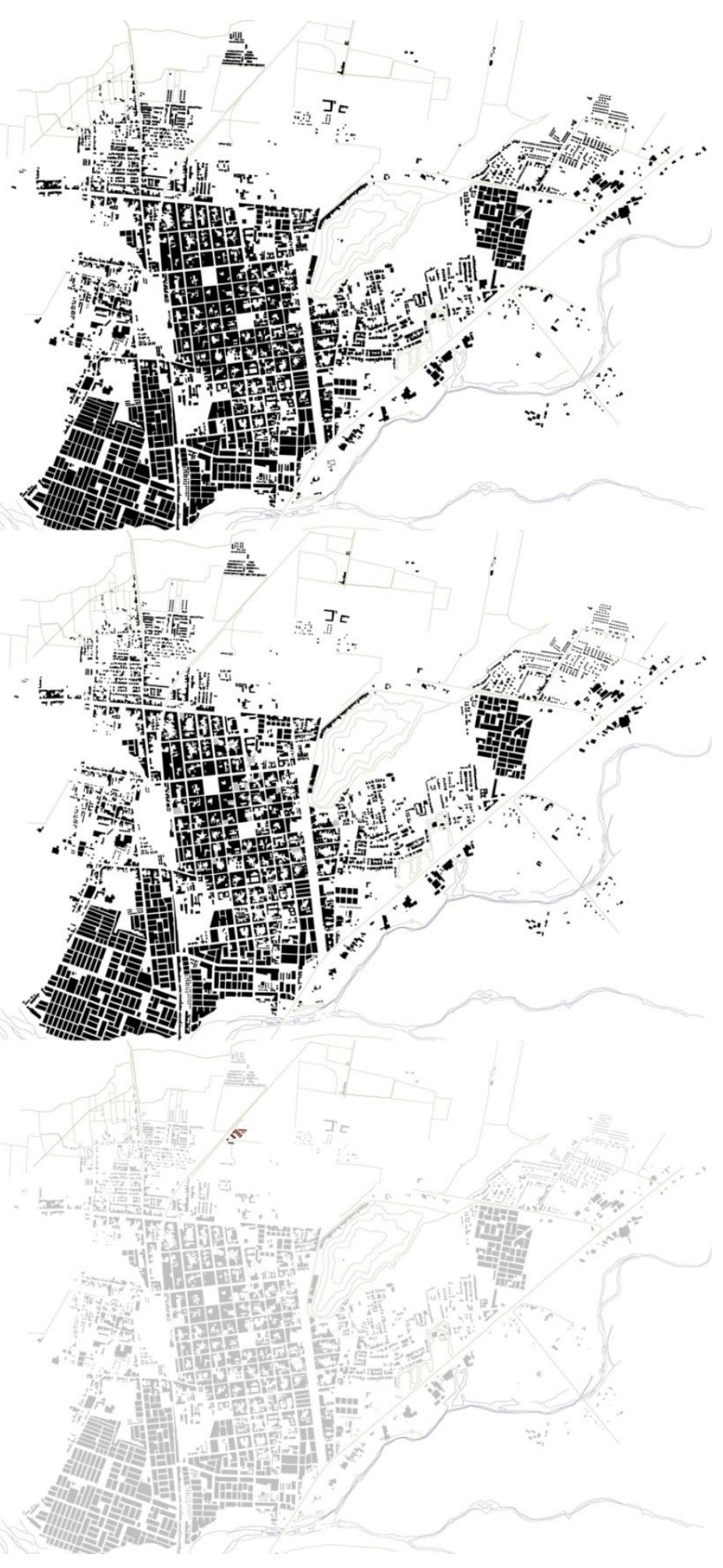




\section{CONCLUSIONES}

Aunque en el contenido de esta comunicación no se presenta el total de la documentación generada con motivo del Proyecto, si podemos concretar una serie de conclusiones de los fallos o ausencias en la re-construcción, alguna de ellas reflejadas en el anterior resumen del monitoreo de datos relativos a la reconstrucción.

1 En las entrevistas con los vecinos percibimos y corroboramos posteriormente con informes realizados por ONG implicadas como Surmauley desde el propio OR que el fortalecimiento y empoderamiento que se pretendía desde el Gobierno Nacional a las comunidades locales no se había dado, pues la participación ciudadana prometida al principio, no había sido tal, y la rapidez en la solución unida a la necesidad de eficiencia productiva habían sido prioritarias. Es significativa esta deficiencia promovida, sobre todo por las constructoras y los actores privados.

2 La deslocalización de sectores de costa como el barrio de la Costanera en Constitución y otros barrios del centro en ciudades del interior de Curicó, ha incrementado procesos de segregación social. No se ha respetado el sentido de pertenencia.

3 Las actuaciones realizadas previendo la integración y mejora de los barrios afectados en cuanto a espacio público y colectivo, no han existido. No se ha regenerado el tejido urbano.

4 Se ha teatralizado el valor patrimonial de los barrios antiguos y se han alterado sus construcciones y tipologías.

5 Se han ofrecido viviendas tipo, estandarizadas que en la mayoría de los casos no cubrían las expectativas de los vecinos.

6 Al no recibir subsidios muchas familias que no disponían de papeles con vínculos de propiedad o arrendamientos, se ha contribuido a la ruptura de entornos familiares, como en el caso de los allegados.

7 Las aldeas fueron concedidas con situaciones transitorias y algunos vecinos aún no han recibido sus viviendas después de casi cuatro años.

En esta relación de deficiencias en la re-construcción y problemas generados a la población afectada, desde nuestra corta perspectiva, se presentan algunas que estaban detectadas en los orígenes del Proyecto de Cooperación, pero otras las hemos descubierto durante la ejecución del mismo, por lo que entendemos que los objetivos específicos del Proyecto se consiguieron en parte, pero ha quedado pendiente una reconsideración y concreción de los mismos, con el objetivo de conseguir unos resultados a corto plazo.

Parte de los resultados de esta cooperación se han conseguido a través de la información técnica que se les ha facilitado a los vecinos, en las reuniones celebradas con los comités de damnificados, capacitándolos para poder entender los planos con los que trabajaban y las características constructivas y patologías de las edificaciones que se les ofrecían y hacer más productivas sus propias reclamaciones a constructoras y entidades públicas. Otra parte de los resultados, se basaba en la transmisión de las informaciones comparativas, a través de los mapeados generados, pero esta información y aporte de reflexiones que se había pensado subir a la web que a tal efecto tiene el Observatorio (OR) del INVI, que 
aún está por realizar y por llegar a los vecinos. Además la interpretación de la misma a través de intercambios directos, no se ha podido realizar en esta primera fase, quedando a la espera de una nueva intervención, que esperamos poder ejecutar en este año, con una mayor concentración de las actividades.

La siguiente fase la queremos concretar en el barrio de la Costanera en Constitución, pues entendemos que habiendo sido un barrio de pescadores que vivían de los recursos ofrecidos por el río Maule antes del tsunami, con las actuaciones del Plan de re-construcción, han perdido estas posibilidades.

Los vecinos han sido en su inmensa mayoría desplazados de su localización originaria y llevado a sectores periféricos, además de la pérdida de sus vecinos y familiares habituales, han perdido la cualidad de sus entornos habitables. Estos vecinos vivían en casas pobres pero extensas, en un medio privilegiado de cara a las expectativas de inversores. Y ahora el Plan de reconstrucción a través de la figura del PRES, ha definido toda esta zona como "Parque de Mitigación Río Maule", previendo ante futuros Tsunamis, una franja verde de arbolado.

Lo cierto es que, hasta la fecha, las orillas del río están aún sin poblar de árboles o sin acondicionar como parque, convertidas ahora en eriales que han aumentado la inseguridad ciudadana, sirviendo de descanso a grupos de perros callejeros abandonados y sin nadie que los cuide o alimente. No olvidemos por otro lado, que son los terrenos más cotizadas por el turismo y por esto los vecinos temen que se pueda seguir el ejemplo de Valdivia, donde los edificios de mayor altura, hoteles y centro comerciales, ocupan la primera línea de costa, porque no podemos olvidad que las propuestas del PRES son realizadas por empresas privadas en este caso la maderera Arauco SA. que se ubica en la zona de costa contigua a la desembocadura al Pacífico y a la que también hay que agradecer la fuerte deforestación del entorno, pero esto es otra cuestión. 


\title{
University and cooperation: Reconstruction in Chile after the earthquake tsunami of 2010
}

\begin{abstract}
Purpose of this presentation is to document one of the possible ways of how cooperation linking practice and research, developed at the University of Seville. On the occasion of the Project of Cooperation" The Reconstruction after the Earthquake- Tsunami in the South of Chile" developed in a 1st phase and financed by the US, we have taken part in the different realities of localities affected by the devastating earthquake - tsunami of 2010, which concerned to the localities of the South of Chile. We have realized the cooperation in collaboration with the group of investigation of I UNSAW of the University of Chile and across the different organizations neighbors' committees and NGOS, related to the damaged ones. The four towns chosen for study and cooperation are: Constitución, Llico, Cauquenes and Curicó, placed in the seventh and eighth region and represent average and small cities, in coastal situation and of interior, affected by the earthquaketsunami.In each one of them locate the demands of a vulnerable population, which has lost the scarce resources that sometimes had and where the re-construction Plan has isolated them even more, sometimes denied the right itself to the city to which they belonged, his neighborhood and customs.
\end{abstract}

KEY WORDS: Development. Cooperation. Urban reconstruction. 


\section{Universidade e Cooperação: Reconstrução no Chile depois do Terremoto tsunami de 2010}

\section{RESUMO}

O objetivo deste trabalho é documentar uma das possíveis formas de ligar a Cooperação para o Desenvolvimento Internacional para a prática de ensino e pesquisa desenvolvida na Universidade de Sevilha. Para marcar Projeto de Cooperação "Reconstrução após o terremoto, tsunami no sul do Chile", desenvolvido na Fase 1 e financiado pelos EUA, temos participado nas diferentes realidades das áreas afetadas pelo devastador terremototsunami de 2010, que afetou as aldeias do sul do Chile. Cooperação que temos feito em colaboração com o grupo de pesquisa INVI na Universidade do Chile e através de diferentes organizações, ONGs e comitês de bairro relacionadas com as vítimas.Os quatro locais escolhidos para a cooperação e estudo são: Constituição, Llico, Cauquenes e Curico, localizado na região sétima e oitava e representam médias e pequenas cidades em situação costeiras e interiores, afetadas pelo terremoto-tsunami.Em cada uma delas localizamos as demandas de uma população vulnerável, que perdeu os escassos recursos que tinha e onde o Plano de Re-construction isolou-los ainda mais, por vezes, negandoIhes o próprio direito à cidade que eles pertenciam, à sua vizinhança e costumes.

PALAVRAS-CHAVE: Desenvolvimento. Cooperação. Reconstrução urbana. 


\section{REFERENCIAS}

BAUMAN, Zygmunt. Vidas Desperdiciadas: La Modernidad y Sus Parias. Paidós Estado y Sociedad. Vol. 126. Barcelona, Ed. Paidós. 2005.

DE SOLÀ-MORALES, Ignasi; SASSEN, Saskia. (2002).Territorios. Barcelona; Ed. Gustavo Gili.

DELGADO, Manuel; UNIVERSIDAD POLITÉCNICA DE VALENCIA. Memoria y Lugar: El Espacio Público Como Crisis De Significado. Memorias Culturales. Valencia, Universidad Politécnica. 2001.

DELGADO, Manuel. Sociedades anónimas. La fuerza del anonimato. Ed. ESPAI EN BLANC Y VV.AA.<http://www.espaienblanc.net/Sociedades-anonimas.html>. Las Trampas de la negociación. 2009.

LEFEBVRE, HENRI.La Production De l'Espace. Ethnosociologie. 4a ed. Paris, Ed. Anthropos. 2000.

LETELIER, Francisco; BOYCO, Patricia. Talca a tres años del terremoto: aprendizajes colectivos para la acción en la ciudad. TEMAS SOCIALES no 70. Santiago. Chile. 2013.

PRIETO, Maria. Red XIV-D.Alternativas y Políticas Habitacionales, CYTED: Hacia un Diagnóstico de la Vivienda Popular en Iberoamerica. Asunción. Arte Nuevo. 1999.

PRIETO, Maria. Intimidades Transgredidas: Habitar en Transito. Proyecto, Progreso, Arquitectura. Vol. Hábitat y Habitar. No. 149. p. 132-149, 2013.

PRIETO, MARIA. Apropiaciones urbanas espontáneas: asentamiento y okupación. Actas Congreso Procesos extremos en la constitución de la ciudad. De la crisis a la emergencia de los espacios mundializados. Sevilla. US. p. 76-97, 2014.

SEPÚLVEDA, RUBÉN.Política habitacional chilena ¿un instrumento para abordar la construcción de un hábitat integral?.Boletín del Instituto de la Vivienda, Chile, 2 Vol. 15 Núm. 41, p. 51-62, 2000.

SEPÚLVEDA, Rubén; LARENAS SALAS, Jorge; otros.Bicentenario: Oportunidad de repensar las políticas urbano-habitacionales en Chile. Revista INVI. Vol. 24, No 67. p. 21-67,2009. 
SEAFORTH, Wandia. Estambul + 5: La opinión de la Red "Viviendo y Construyendo" a cinco años de la Conferencia Hábitat II. Boletín INVI no 45. Vol. 17: 98 a 107. 2002.

WIRTH, Louis.El Urbanismo como modo de vida. Cuadernos Del Taller. Buenos Aires, Ediciones 3. 1962. 
Recebido: 15 fev. 2016.

Aprovado: 25 abr. 2016.

DOI: $10.3895 /$ rbpd.v5n1.4450

Como citar: PEINADO, M. D. P.; FERNÁNDEZ-VALDERRAMA, L. Universidad y cooperación:

Reconstrucción en Chile tras el terremoto tsunami de 2010. R. bras. Planej. Desenv.,Curitiba, v. 5, n. 1, p.

152-180, jan./abr. 2016. Disponível em: <https://periodicos.utfpr.edu.br/rbpd>. Acesso em: XXX.

\section{Correspondência:}

María Dolores Prieto Peinado

Calle San Fernando, 4, 41004 Sevilla, Espanha

Direito autoral: Este artigo está licenciado sob os termos da Licença Creative Commons-Atribuição 4.0

Internacional. 